\title{
Jean-Paul Sartre e Ferreira Gullar: engajamento e trabalho
}

\section{Juarez Poletto}

Doutor em Letras. Professor da UTFPR, campus Curitiba. Escritor.

Resumo: o ensaio inicialmente resenha Que é a literatura?, de Jean-Paul Sartre, a fim de detectar como o filósofo entende o papel da poesia no engajamento da arte e do artista. Num segundo momento, aborda a produção do poeta Ferreira Gullar, até a obra Dentro da noite veloz (publicada em 1975) e em torno do motivo poético do trabalho, para contrapor a criação do escritor à teoria do filósofo e assim afirmar que poesia também pode engajar-se.

Palavras-chave: poesia, engajamento, trabalho, Sartre, Ferreira Gullar

\section{I}

Em meados do século $X X$, é inegável que o engajamento ocupou espaço privilegiado nas discussões sobre literatura. Isso se deve, em boa parte, à figura singular de Jean-Paul Sartre, a seus estudos filosóficos e literários, bem como as suas atitudes provocativas em escritos irreverentes. É ele quem constrói a tese da literatura engajada e é a partir de seu posicionamento que a polêmica em torno do termo adquiriu dimensão. Cabe, então, olhar mais de perto como, para seu idealizador, se dá o engajamento, nos moldes como ficou conhecido.

O livro Que é a literatura? foi organizado em quatro partes, precedidas de um prefácio do próprio Sartre onde levanta as questões que lhe são freqüentemente dirigidas a propósito do engajamento da literatura e das artes e afirma que sua resposta será "examinar a arte de escrever, sem preconceitos" "il]. É isso que ele se dispõe a realizar nos três capítulos inicias do livro, que se intitulam, respectivamente, "Que é escrever?", "Por que se escreve?", "Para quem se escreve?". O quarto capítulo discute a "Situação do escritor em 1947". A preocupação central deste estudo está relacionada ao primeiro capítulo, embora se façam incursões pelos demais.

Sartre inicia "O que é escrever?" afirmando: "Não, nós não queremos 'engajar também' a pintura, a escultura e a música" (p. 9), respondendo, desse modo, às questões que lhe impunham críticos sobre sua atitude engajada. Mas Sartre está projetando também, com a afirmação, que cada arte tem sua peculiaridade e que nem todas são engajáveis, pois "uma coisa é trabalhar com sons e cores, outra é expressar-se com palavras. As notas, as cores, as formas não são signos ${ }^{[i i]}$, não remetem a nada que thes seja exterior" (p. 10). O filósofo francês compreende a música ou a pintura como coisa em si e não como meio para alcançar um fim, pois já são um fim. A pintura e a música não podem ser engajadas, porque apresentam algo diante do que se pode ver ou perceber o que se quiser. Sartre exemplifica citando que o casebre desenhado pelo pintor não pode ser o símbolo da miséria, mas se mostrado por um prosador este pode dirigir o leitor para revelar no casebre o símbolo das injustiças sociais e então provocar a indignação. O mesmo ocorreria se desenhasse um operário. "E o que pensar de um operário? Uma infinidade de coisas contraditórias. 
Todos os pensamentos, todos os sentimentos estão ali, aglutinados sobre a tela, em indiferenciação profunda; cabe a você escolher" (p.13). Para Sartre, não é possível pintar ou transformar significados em música, por isso não é possível engajar essas artes.

O citado operário, se desenhado, é coisa, se escrito é signo, então significado. Afirma Sartre que "o império dos signos é a prosa" (p. 13), pois ela lida com os significados. Note-se que a reflexão se refere à prosa que, para Sartre, difere da poesia, porque "a poesia está lado a lado com a pintura, a escultura, a música" (p. 13). Não é porque use palavras, como a prosa, que a poesia deva ser considerada engajável, até porque "a poesia não se serve de palavras [...]. Os poetas são homens que se recusam a utilizar a linguagem" (p. 13). Observe-se o destaque que Sartre dá aos termos 'serve' e 'utilizar', sugerindo exatamente o sentido não utilitário ou de intermediação que a linguagem pode ter ou normalmente tem.

Para Sartre, a linguagem da poesia, ao criar seu mundo e suas coisas, causa algo que se assemelha à visão de estranhamento proposta pelos formalistas russos, que pensavam a poesia como um sistema de signos orientados para a expressão e não a comunicação, que fica em segundo lugar. A palavra, para o poeta, não é utilizada como signo (no conceito saussuriano), pois adquire uma dimensão morfológica e sonora, em que o significante é que importa e não a representação das coisas pelo significado. Sartre compreende a linguagem da prosa similar à da informação, capaz de dizer o mundo sem subterfúgios, por isso adequada para o engajamento do artista, pois se faz inteligível, ainda que original em seu estilo. "O prosador [é] um homem que se serve das palavras" (p. 18), diferentemente do poeta que, ao empregar a palavra, não mais consegue usá-la para significar algo, porque a palavra se torna substância. De tal modo, fica impossível o engajamento do poeta, pois as motivações para a poesia não se exprimem no poema, mas lhe estão na origem. Ou seja, seguindo o pensamento sartreano: a indignação social, a raiva, o ódio político ou qualquer outro propósito existem anteriores ao poema, porque no poema essas paixões se transformam em palavras, a emoção se faz coisa e por isso se torna opaca, ambígua e perde a propriedade de designar, de esclarecer, de expor. Isso porque para o poeta diferentemente do que ocorre com o homem comum que se comunica - as palavras "são coisas naturais que crescem naturalmente sobre a terra, como a relva e as árvores" (p. 14).

Para Sartre, a linguagem é um instrumento com o qual se busca a verdade, mas "não se deve imaginar que os poetas [pretendam] discernir o verdadeiro, ou dá-lo a conhecer. Eles tampouco aspiram a nomear o mundo" (p. 13). Nomear é intermediar a relação entre o homem e a coisa, mas "o poeta se afastou por completo da linguageminstrumento; escolheu de uma vez por todas a atitude poética que considera as palavras como coisas e não como signos" (p. 13). O poeta, portanto, para Sartre, não diz algo, não comunica claramente, não designa, porque para ele a linguagem não é intermediação entre os homens, mas constituição de objetos. O poeta, por isso, não usa o verbo de modo convencional e não pode ser engajado, pois não pertence ao 
campo utilitário do uso da linguagem, porque esse mundo é o da prosa. É fundamental ter em mente que o poeta, para Sartre, pode romper com a relação significado/significante, segundo a lingüística sausseureana, e fazer "acasalamentos monstruosos" (p. 13) de palavras como "cavalo de manteiga" (p. 13), o que seria um contra-senso, já que retiraria a utensilidade das palavras. Neste caso o significante já é a coisa e não a remissão a ela. Ao poeta são possíveis essas associações inusitadas de palavras que alucinem, o que não cabe ao prosador, que precisa ser lúcido para se fazer entender.

Isso que Sartre denomina de "acasalamentos monstruosos", Hugo Friedrich ${ }^{\text {[iii] }}$ chamou de "dissonância" e de "categorias negativas", não porque fossem expressões que quisessem estragar o mundo e a linguagem, mas porque a incompreensibilidade fascina e gera inquietude. A poesia moderna desorienta e dissolve o que é corrente, daí uma obscuridade intencional dos poetas, numa linguagem que adquire caráter de experimento, com combinações inusitadas. A palavra poética não mais queria soar de acordo com o mundo, daí a dissonância e os arranjos que causavam perplexidade; o verbo não mais funcionava como a construção dos valores burgueses, mas como seu esfacelamento, então as categorias negativas.

Sartre, em seguida e ainda argumentando sobre o fazer da poesia, compara o que é a linguagem para o falante a para o poeta. Para aquele, as palavras "são os prolongamentos de seus sentidos [...] [com os quais] estende sua ação sobre o mundo" (p. 14); para o poeta, as palavras estão do lado de fora, "como se não pertencesse[m] à condição humana" (p. 14). Então o poeta não conhece as coisas por seu nome, pois não se serve da palavra como signo, mas aproxima as palavras das coisas por ver entre elas afinidades, como se visse na palavra a própria coisa. "E a imagem verbal que ele escolhe por sua semelhança com o salgueiro ou o freixo não é necessariamente a palavra que nós utilizamos para designar esses objetos" (p. 14). Então a palavra é um corpo com suas marcas identificadoras: som, aspecto visual, tamanho, terminações (membros), "tudo isso junto compõe para ele um rosto carnal, que antes representa do que expressa o significado" (p. 15), daí se estabelece entre a palavra e a coisa "uma dupla relação recíproca de semelhança mágica e de significado" (p. 15) que gera a polissemia. Por isso a palavra poética não cabe no engajamento, pois ela perde sua precisão e o poeta convida o leitor a se posicionar também fora da linguagem, como se olhasse o mundo pelos olhos de Deus e visse as coisas em seu estado original. O poeta afasta o leitor da condição humana, afirma Sartre, então “como esperar que o poeta provoque a indignação ou o entusiasmo político do leitor [...]" (p. 18)?

\section{II}

No contraponto à produção de alta qualidade técnica está o caminho adotado por Ferreira Gullar, no início dos anos sessenta, quando adotou o romance de cordel como meio, segundo ele mesmo, para reencontrar a poesia. Pretendia, depois de experiência na poesia Concreta - onde vislumbrou a esterilidade criativa - achar o rumo 
perdido, então voltou às origens populares do verso narrativo engajado. Paralelamente criou alguns dos poemas que constam de Dentro da noite veloz (1975). A essa fase em que esteve também envolvido diretamente no CPC (Centro Popular de Cultura) da UNE, antecedeu outra, a da Luta corporal (entre 1950 e 1953), seu primeiro livro, O vil metal (1954-1960) que the sucedeu e dos Poemas Concretos/Neoconcretos (1957-1958). Esse período foi de envolvimento com a vanguarda poética, de pesquisa formal crescente até chegar ao impasse que o levou ao cordel.

Nessa primeira fase de sua poesia, o motivo poético do trabalho marca presença numa gradação decrescente, ainda assim não se trata do trabalho pragmático que gera sustento à vida física. Em $A$ luta corporal, são dez poemas que mencionam a palavra trabalho, mas na maior parte as "nuvens trabalham" Trabalha / no vazio" (p. 37), há o "doloroso trabalho / das coisas" (p. 39), existe o “trabalhar-se! não se concluir nunca!" (p. 43), "Um céu vertiginoso trabalha” (p. 55), “O mar lapida os trabalhos / de sua solidão" (p.97). A palavra está presente, mas quase sem referência ao homem, são as coisas que trabalham, como se a natureza fosse ativa e expressasse uma vontade. Em apenas uma vez a referência é ao homem e nesse caso não foi empregado o termo trabalho, mas "sob que nuvens os homens arquejam" (p. 57), numa indicação do sofrimento possivelmente pelo esforço do trabalho. Outras duas vezes a menção a trabalho aponta o fazer poético, como: "Assim é o trabalho. Onde a luz da palavra / torna à sua fonte" (p. 90) e "O odor / do corpo é impuro, / mas é preciso amá-lo. / Nenhum outro sol me clareia, / senão esse, mortal / como um pássaro, / que meu trabalho acende / desse odor" (p. 93). No penúltimo exemplo está destacada a palavra poética em busca da origem ou de ser original; no último, a poesia se origina no odor impuro da vida, o trabalho do poeta se quer exalando existência. Esses dois excertos finais contêm os dois pólos pelos quais transita a poesia de Ferreira Gullar: o apelo à palavra original e o apego à realidade humana. A poesia para Gullar, como afirma em "Cultura Posta em Questão", pode ser engajada e ainda assim "abrir perspectivas novas para a criação poética". ${ }^{[\mathrm{v}]}$ Dentro dessa perspectiva se pode compreender a obra Dentro da noite veloz como inserida nas angústias existenciais humanas de uma época e ao mesmo tempo como construção lingüística dessas angústias.

De certa forma se pode também compreender a incursão do poeta pela poesia de cordel, como de alguém que não encontrou respaldo ou caminho na vanguarda poética de caráter formal da época para comportar sua ânsia de criar a vida em versos, de construir o medo, a perseguição, as diferenças sociais, a morte e a luta por mudanças em palavras. Esse retorno às origens, no que tange o motivo do trabalho, criou "João Boa-Morte: Cabra marcado pra morrer" "[vi]. Poema construído em versos de redondilha maior, como de praxe em cantos populares, com estrofes irregulares, mas com rimas. O vocabulário é simples, para a compreensão do povo, e a narrativa cria a oposição entre o poder dos coronéis, donos das terras nordestinas, e o trabalhador dessas terras, que vive a penúria do dia-a-dia, sem perspectivas de 
melhorar sua condição de vida. O relato mostra a ausência de resultado positivo do trabalho para o trabalhador explorado e acompanha a disputa entre coronel e trabalhadores pelo preço dos produtos e pela liberdade de venda deles. Nessa disputa, o coronel usa seu poder de intimidação e mata, com seus jagunços, os que não se submetem. João Boa-Morte, dada sua condição de miserabilidade e o sofrimento da família, resolveu enfrentar o coronel Benedito conclamando os companheiros à reação. Mas o que lhe aconteceu foi perder o lugar onde trabalhava e ter que vagar com a família passando fome e não sendo aceito em lugar nenhum como represália por ter enfrentado o patrão. Em andanças e fome por longo período e distância, morreu o filho mais moço. João, em desespero e sozinho, pensou em matar o resto da família e depois se matar também. Quando estava para executar sua sina, Chico Vaqueiro o encontrou e o demoveu do crime, convencendo-o a lutar junto de companheiros da Liga Camponesa que organizavam a resistência contra os coronéis. O poema termina com a exortação de que, para mudar a situação, é preciso unir o camponês para realizar a revolução. Em essência, o poema resume a sina de muitos sertanejos posseiros de terras ou sem-terra, que ousassem liderar qualquer movimento de mudança na relação com os coronéis para quem trabalhavam, que tratavam o homem livre em regime similar ao da passada escravidão.

O poema traduz o canto que conclama o povo à resistência contra a exploração de seu trabalho, não apresenta singularidades formais a não ser a simplicidade de versos populares, e nem é intenção ser diferente, pois quer ser o que é: denúncia. Não há especulação ou inovação formal nos versos, apenas integração do poeta com as agruras da vida rural de seu tempo e dos movimentos de conscientização levados ao campo pela organização comunista das Ligas Camponesas. O poeta está dizendo que não pode passar imune a essa realidade e que precisa não só compor a poesia da e para a elite na sua perseguição à inovação e renovação intelectual, mas também dizer do homem comum em linguagem comum, o sofrimento comum para comover e conquistar. É o poeta buscando comunicação fora de seu espaço característico e para isso precisa adequar sua palavra. Tempos de exceção requerem medidas de exceção.

Ferreira Gullar atacou em duas frentes: primeiro dedicou-se à produção de cordel, mas ainda nos anos sessenta compôs alguns dos poemas que viriam à luz em seu livro Dentro da noite veloz, publicado apenas em 1975. Nessa obra, o poeta disse ao mundo das letras que não perdera o jeito para a poesia, mas não a queria mais vanguarda estéril, então a apontou em outro sentido em “Meu povo, meu poema”" ${ }^{\text {,Viil }}$, onde afirma que "Meu povo e meu poema crescem juntos" e são "como o sol / na garganta do futuro". O poeta quer contribuir para a construção de nova vida e de nova poesia, por isso povo e poema se fundem e na terra fértil da vida se forja uma nova espiga. Sua poesia se quer menos canto e mais semeadura, mas não se furta ao canto, pois está elaborada tecnicamente.

Meu povo e meu poema crescem juntos como cresce no fruto a árvore nova 
No povo meu poema vai crescendo como no canavial nasce verde o açúcar No povo meu poema está maduro como o sol na garganta do futuro Meu povo em meu poema se reflete como a espiga se funde em terra fértil Ao povo seu poema aqui devolvo menos como quem canta do que planta.

As imagens desse poema já não remetem à construção popular dos versos: não há regularidade métrica, mas as estrofes todas têm três versos cada uma; não há preocupação também com a regularidade das rimas, mas elas aparecem para ampliar significações, como acontece com "maduro/futuro" ou "canta/planta". O futuro é mais, se maduro; e o plantio alcança melhor sua meta, se também canto, o que põe juntos a ação social e a criação artística. O texto inteiro está construído na associação entre povo e poema e relacionado aos eventos de crescimento na natureza. Assim na primeira estrofe está presente a imagem do fruto que nele contém a árvore nova: "Meu povo e meu poema crescem juntos / como cresce no fruto / a árvore nova". O fruto é o poema, a árvore nova é a nova sociedade. Na segunda estrofe, a associação está feita com o canavial, que funciona como o poema, enquanto o açúcar proveniente dele é a vida nova e mais doce que se pretende criar: "No povo meu poema vai nascendo / como no canavial / nasce verde o açúcar". Na terceira estrofe, o poema é sol, a voz a cantar o amanhã, pois é uma luz que se encontra na "garganta do futuro". Então na quarta estrofe, povo e poema funcionam como imagem e espelho que se encontram e, da terra fértil, funde-se uma nova espiga. Essa espiga tem a dupla simbologia: ser o projeto futuro e também o poema acabado que, na última estrofe, o poeta devolve ao povo como semente, já que se construiu como espiga e, portanto, contém grãos que alimentam e se replantam.

Após romper com o Concretismo, sua idéia de criação poética se transforma e passa primeiro pelo poema popular engajado, depois retorna à poesia propriamente, mas não mais preso às contingências formais de uma estética ou vanguarda. A poesia precisava fazer um sentido social, necessitava contribuir para a mudança da realidade humana que o poeta via oprimida e opressora, sempre com prejuízo para o homem comum, o trabalhador rural ou citadino, como se pôde constatar no poema-cordel e se pode ver em poemas de Dentro da noite veloz, como "Poema Brasileiro", "Não Há Vagas", "Açúcar", “Agosto de 1964" entre outros tantos. Gullar mergulhou na tenebrosa realidade de seu tempo das Ligas Camponesas e das lutas sindicais e cantou as desigualdades em versos desiguais, como se ampliasse seu canto para ser mais ouvido, queria atingir os ouvidos da intelectualidade e os do povo, então escreveu o cordel e o poema de elaboração formal. Gullar, pois, contraria Sartre, que não via a poesia como arte engajada, e o poeta brasileiro também considera o engajamento nem como fruto de equívoco nem como oportunismo, como alguns estudiosos e críticos apregoam, porque o poema engajado pode "cumprir com as exigências de formulação do seu conteúdo" e ainda se pergunta: "só pode a poesia exprimir perplexidades ou 
pode também exprimir uma consciência clara do mundo?". Defendendo a complexidade do fenômeno literário e não negando as posições contrárias ao engajamento como teoricamente possíveis, Ferreira Gullar batalha por um espaço para a poesia engajada, pois entende que a literatura é "um dos vários campos em que se formulam e exprimem as experiências humanas em toda a sua amplitude, aberto portanto à realidade dos fatos e dos problemas dos homens". Se assim entendido o fenômeno literário, será mais fácil compreender o engajamento como resultante "de uma maior pressão da realidade social sobre a realidade literária". [viii]

[i] SARTRE, Jean-Paul. Op. cit. p. 7. As próximas citações desta obra virão seguidas apenas do número da página em que se encontra.

[ii] Sartre se refere a 'signo' no conceito saussuriano.

[iii] FRIEDRICH, Hugo. Estrutura da lírica moderna: da metade do século XIX a meados do século XX. Trad. do texto: Marise M. Curioni; Trad. das poesias: Dora F. da Silva. São Paulo: Duas Cidades, 1978, p. 15-34.

[iv]

GULLAR, Ferreira. Toda poesia (1950-1980) . 3 ed. Rio de Janeiro: 1983, p.35. As demais indicações do parágrafo virão apenas com a indicação da página após a citação.

[v] GULLAR, Ferreira. Cultura posta em questão \& Vanguarda e subdesenvolvimento. Rio de janeiro: José Olympio, 2002, p. 101.

[vi] GULLAR, Ferreira. Toda poesia: 1950-1980. Op. cit. p. 177.

[vii] GULLAR, Ferreira. Toda poesia:1950-1980. Op. cit. p. 217. A organização seqüencial dos poemas no livro e a indicação de que são produções iniciadas em 1962, permitem supor que as dez primeiras composições pertençam ao período entre 1962 e 1964, ao menos se referem a esse tempo.

[viii]

GULLAR, Ferreira. Cultura posta em questão \& Vanguarda e subdesenvolvimento. Op. cit. p. 101. 